\title{
PABLO LATAPÍ, MAESTRO EJEMPLAR (2009)
}

Don Pablo es luz y ha proyectado luz sobre inmensas oscuridades.

\section{Pienso que no es exagerado atribuir a} Pablo Latapí la descripción que hace Luis Vives del vir doctus: la razón de este género de vida es doble — dice Vives_- En primer lugar, porque las artes de las humanidades nos hacen más humanos y, en segundo lugar, porque el homo eruditus, con su modo de ser, con sus palabras sabias y acertadas, con su sabiduría, es la luz y la verdad del mundo. "El Homo eruditus - agrega — tiene como misión trasmitir a los demás su saber como quien enciende en las mentes de otros luz de su propia luz. Por eso se dice en la visión de Daniel que quienes enseñaron a otros la justicia relucirán eternamente como estrellas perpetuas." Pablo Latapí es ese vir doctus, ese Homo eruditus del que habla Vives. Pablo Latapí es luz y verdad del mundo.

$\mathrm{Si}$, como dice Gusdorf, la educación consiste en el diálogo incierto entre personalidades de distinta madurez humana que dan testimonio de humanidad; y si es cierto que el maestro educa más con lo que es que con lo que dice, Pablo Latapí es y ha sido un gran maestro, porque su vida, toda su vida, es testimonio de verdad, de justicia, de humanidad.

Una de las luchas más intensas y valientes de Pablo Latapí ha sido la apasionada defensa de la dignidad universitaria y de la educación humanista.

En esta época en que las universidades, sin ningún recato, se han entregado a los brazos del mercado y rigen sus acciones según fines mercantiles, la voz de don Pablo ha sido la denuncia pero también ha 
anunciado y descrito la auténtica formación: el desarrollo del pensamiento crítico, de la imaginación, de la creatividad, de la responsabilidad social, de la adhesión a los valores permanentes.

No hay que continuar el camino de la memoria que repite y conserva este sistema en tantos aspectos perverso. Urge inventar, dice Latapí, un modo de convivencia humana mucho más justo y más humano en el que las personas no sean tratadas como mercancías, como medios de producción de dinero.

Para aquellos que piensan que don Pablo es un pedagogo que mantiene y construye sus teorías en el plano de la abstracción, allí están todos sus escritos, incontables escritos, sobre los más candentes problemas nacionales: problemas del magisterio, de la educación superior del federalismo, de la política social, de los dramas de Chiapas.

No me resisto a citar un largo párrafo de su artículo "La visión de los vencidos", en el que increpa al entonces presidente Ernesto Zedillo cuando envió las tropas del ejército a Chiapas. Juzguen ustedes si el contenido y la forma son de un teórico abstraído de la realidad:

Termino con esta respetuosa palabra dirigida al presidente Zedillo, a quien traté como secretario de Educación Pública: Considero errónea y trágica, señor presidente, su decisión de militarizar el Estado de Chiapas, porque no conducirá a la paz y porque está teniendo terribles consecuencias para las comunidades a donde llegan las Fuerzas Armadas...

No sé de política, señor presidente; pero por estos medios no conseguirá Ud. una paz digna y justa; el camino está equivocado y, además, es éticamente insostenible. Su estrategia de paz lo llevará, sin que Ud. lo quiera, a la violación de los derechos humanos de muchos inocentes y al exterminio de los indígenas chiapanecos. Quienes en el pasado lo hemos apreciado no deseamos que su nombre figure en las crónicas futuras como el triste triunfador de los nuevamente vencidos. Ud. no requiere de acciones violentas para fortalecer su imagen. La verdadera fortaleza de un gobernante, la que convence y perdura, es la que le da su calidad moral. Un presidente conciliador, magnánimo, generoso y justo es más fuerte que el que mata y amedrenta; su fuerza es la de la unidad de sus gobernados. Así deseamos poderlo recordar. 
Una ocasión muy especial en que tuve el privilegio de platicar amplia y tranquilamente con don Pablo fue cuando lo invité a comer para recordar su valiosísima participación en la restructuración del programa académico del ITAM correspondiente a los primeros semestres.

El Instituto Tecnológico Autónomo de México siente un profundo agradecimiento a Pablo Latapí por su lúcida aportación en la elaboración del programa distintivo de esta institución, a la que llamo "Universidad dentro del Tecnológico" y que tiene como encargo específico la formación humanista de los estudiantes con siete materias obligatorias y algunas optativas. Me refiero al programa que lleva el nombre de las instituciones que después fueron llamadas universidades: estudios generales (studia generalia).

Don Pablo y yo siempre coincidimos en que solo hombres de gran calidad humana pueden salvar a México. Solo hombres de ética vivida, hombres que digan la verdad y sean verdad, hombres que defiendan con pasión sus convicciones pero también que admitan la certeza de la falibilidad de su certeza para no caer en el fundamentalismo.

Parece que las más fuertes corrientes educativas han optado por el amaestramiento, por el adiestramiento para responder a las exigencias pragmáticas del mercado y de los mercaderes. Se considera el humanismo como idealismo utópico y vetusto. Es fuerte la lucha entre el Homo oeconomicus y el Homo sapiens, entre el valor de las personas, de la dignidad de las personas y el valor del dinero.

En estos tiempos, en que también se menosprecia la educación del hombre-humano, se ataca a la razón como la gran culpable de los mayores males (posmodernidad), ahora que se prefieren las ingenierías para entender a las máquinas que la filosofía y las ciencias humanas; ahora que quiere imponerse el subjetivismo, el relativismo y el nihilismo, es indispensable y urgente que vibre con fuerza la voz de Pablo Latapí, que sigue defendiendo la dignidad de la persona, los valores perennes, que defiende con pasión la verdad y la vida, la justicia, la libertad y el poder del espíritu. 
CITAM Derechos Reservados.

La reproducción total o parcial de este artículo se podrá hacer si el ITAM otorga la autorización previamente por escrito. 